\title{
Effects of Apomorphine on Elicited and Operant Pecking in Pigeons
}

\author{
Joanne S. Abelson ${ }^{1}$ and James H. Woods ${ }^{2}$ \\ 1 CNS Pharmacology Section, Warner-Lambert/Parke-Davis Research Labs, 2800 Plymouth Rd., Ann Arbor, MI 48105, USA \\ 2 Departments of Psychology and Pharmacology, University of Michigan, Ann Arbor, MI 48104, USA
}

\begin{abstract}
The effects of apomorphine (0.001$32.0 \mathrm{mg} / \mathrm{kg}$ ) on elicited and operant pecking were studied in pigeons. Elicited pecking was measured in a 1-h observation test. Apomorphine caused dose-related increases in the pecking elicited by the drug in all the subjects, with maximal responding at $3.2 \mathrm{mg} / \mathrm{kg}$. In contrast, operant responding on a multiple, $5 \mathrm{~min}$ fixed interval, 30 response fixed-ratio schedule revealed individual differences in sensitivity to the drug. A dose of $0.32 \mathrm{mg} / \mathrm{kg}$ eliminated key pecking in fixed-interval and fixed-ratio components in 4 (group 1) of the 15 subjects while $3.2 \mathrm{mg} / \mathrm{kg}$ eliminated responding in 9 other subjects (group 2), and 2 of the subjects (group 3) required $32.0 \mathrm{mg} / \mathrm{kg}$ to eliminate responding. The 13 birds in groups 1 and 2 showed decreases in operant responding with concomitant increases in elicited pecking. For the 2 remaining birds, increases in operant behavior were highly correlated with increased stereotypy. The effects of apomorphine on operant behavior appeared to depend on induced stereotypy, with rate-decreasing effects resulting from the disruption of ongoing behavior by stereotyped pecking aimed elsewhere in the chamber, and rate increases resulting from the redirection of elicited pecking towards the operant key.
\end{abstract}

Key words: Apomorphine, behavioral effects - Operant behavior, apomorphine effects - Pigeons, operant behavior, stereotypy - Drug-induced dopamine agonists, behavioral effects

Dopamine agonists such as apomorphine have long been known to elicit stereotyped behavior in a number of species. The intensity and duration of such stereotyped behavior has been found to be positively related to drug dose (Koster 1957; Dhawan and Saxena

\footnotetext{
* Address reprint requests to: J. S. Abelson
}

1960; Ernst 1967). The dog, for example, engages in dose-related stereotyped running behavior, which can be inhibited by dopamine antagonists (Nymark 1972). In the rat, low apomorphine doses produce periodic head and limb movements, while higher doses yield continuous gnawing, bitting, and licking (Costall and Naýlor 1975). In mice, apomorphine elicits sniffing, licking, and biting (Pederson 1967), and stereotyped chewing is produced in the guinea pig (Frommel et al. 1965). In avian species such as pigeon, sparrow, hen, and quail, apomorphine-induced behavior takes the form of dose-related, persistent, and continuous pecking (Deshpande et al. 1961). Saxena et al. (1977) have described a 'pecking syndrome' induced by apomorphine in the pigeon - a sequence of behaviors including preening, visual exploratory movements, and pecking - which appears to reproduce normal feeding behavior patterns.

Investigations of the relationship between apomorphine and ongoing operant behavior have found that its effects depend, as with other drugs, on such variables as the dose, the individual sensitivity of the subject, and the type of response being measured. De Olivera and Graeff (1972) found that apomorphine doses of $0.1-$ $3.0 \mathrm{mg} / \mathrm{kg}$ decreased rates of lever pressing in rats. However, Butcher (1968) found that injections of $0.4-$ $1.0 \mathrm{mg}$ apomorphine $/ \mathrm{kg}$ produced individual differences in continuous avoidance responding in rats; 5 of 11 animals showed decreased lever press rates, while 6 subjects showed rate increases. Similarly, Weissman (1966) found that apomorphine doses from 0.5$8.0 \mathrm{mg} / \mathrm{kg}$ decreased operant responding in 4 pigeons but greatly stimulated responding in a fifth bird. Graeff and De Olivera (1975) examined key pecking and treadle pressing in separate components of a multiple fixed-interval schedule in pigeons. Doses from $0.1-$ $1.0 \mathrm{mg}$ apomorphine $/ \mathrm{kg}$ eliminated treadle pressing in all 5 pigeons. Key pecking was eliminated in 2 subjects, but in 3 subjects key pecking was markedly stimulated. 
Thus, while the rate-decreasing effects of apomorphine on operant behavior seem to predominate, some subjects show paradoxical increases in rate. To account for such findings, it has been postulated that an occasional subject might redirect its stereotyped responding toward the operant manipulandum and thereby generate high operant rates (De Olivera and Graeff 1972). The present study examined the extent to which apomorphine-induced pecking accounts for changes in operant responding by studying the effects of the drug on both elicited and operant behavior in the same subjects.

\section{Materials and Methods}

Subjects. The subjects were 15 male White Carneaux pigeons purchased from Palmetto pigeon farm. The animals were housed individually in aluminium and wire mesh cages $(44 \times 30 \times 28 \mathrm{~cm})$ and allowed free access to water and grit. After experimental sessions they were fed Purina Racing Pigeon Checkers to maintain them at $80 \%$ of their free feeding weight. All subjects had been used previously in studies of drug effects upon learned behavior. The animals had not been used for experimental work for approximately one month prior to the start of the experiment.

Apparatus. Operant experiments were carried out in chambers essentially as described by Ferster and Skinner (1957). The chambers were contained within light- and sound-attenuating enclosures. In the center of one wall of each chamber was a response key $(1.9 \mathrm{~cm})$ located $24.5 \mathrm{~cm}$ above the floor. The response key could be illuminated by a pair of green or red 7-W light bulbs. Mixed grain was delivered through a rectangular opening $12 \mathrm{~cm}$ below the response key. White noise $\left(75 \mathrm{db}\right.$ re $\left.0.0002 \times 10^{-5} \mathrm{~N} / \mathrm{cm}^{2}\right)$ and a white houselight were continuously present during experimental sessions. A white light was illuminated over the grain hopper during food delivery.

Procedure. Key pecking was maintained under a multiple, 5-min fixed interval, 30 response fixed-ratio schedule. Under this schedule, in the presence of a green light the first response after $5 \mathrm{~min}$ (FI5) resulted in 4-s access to mixed grain (reinforcement); alternately, 30 responses (FR30) in the presence of the red light resulted in reinforcement. A 1-min limited hold period was in effect during both components of the multiple schedule; in the FI component, the subject had 1 min at the end of the $5 \mathrm{~min}$ in which to make a response or the schedule would automatically change to FR with no reinforcement given. Similarly, in the FR component the subject had to respond 30 times in $1 \mathrm{~min}$ to obtain access to food. Each session consisted of ten presentations of each component in alternation, always beginning with the fixed interval. Operant sessions were conducted Monday through Friday and lasted approximately $1 \mathrm{~h}$.

A TI-960A computer controlled the progression of the schedules and delivery of reinforcement. The number of reinforcements, response rates (responses per second), and FI quarter-life values were also calculated by computer. Fixed-interval quarter life represents the amount of time taken to produce one quarter of the total number of responses in a given FI period.

Elicited-behavior experiments were conducted in the home cages. Each subject was observed for $1 \mathrm{~min}$ every $15 \mathrm{~min}$ for $1 \mathrm{~h}$ following drug injection. During that time both the number of pecks and the targets of pecking were recorded, and general behavioral observations were made. Pecks were defined as motions where the head was extended from the body in a sharp and deliberate manner. Data were calculated as average responses per second.

Drug. Apomorphine hydrochloride was prepared in distilled water on the day of the drug session; the dose was calculated in terms of the
$\mathrm{HCl}$ salt. Injection volume was always $1 \mathrm{ml} / \mathrm{kg}$. Injections were given into the breast muscle immediately prior to test sessions. Drug was administered on Tuesday and Friday.

In the operant setting, apomorphine was tested in half-log unit doses from $0.001-32.0 \mathrm{mg} / \mathrm{kg}$. Doses were given in random order and at least twice to each subject. In occasional cases, if two observations with a single dose were highly discrepant a third observation was run and the mean of the two most similar observations was calculated. Data collected from the day preceding a drug day served as control. In addition, saline controls were run on three occasions per subject.

In the elicited behavior studies, apomorphine doses were given randomly to all subjects in half-log unit intervals from 0.032 $10.0 \mathrm{mg} / \mathrm{kg}$. In addition, 2 subjects were given $32.0 \mathrm{mg} / \mathrm{kg}$. Animals were injected and immediately returned to their home cages for observation.

\section{Results}

The effects of apomorphine on elicited pecking showed several consistent trends. Pecking was first observed at $0.1 \mathrm{mg} / \mathrm{kg}$ and reached a maximum in the range of $3.2 \mathrm{mg} / \mathrm{kg}$. The effect of increasing apomorphine dose was to decrease the latency to elicit pecking while increasing both the rate and duration of the elicited behavior. Other elements of the 'pecking syndrome' (Saxena et al. 1977), preening and visual exploration, were noted in most birds. Elicited pecking was usually directed at the floor or walls of the cage, sometimes at a pigeon's own body, and often at a point of visual contrast. For a given bird, the targets of pecking were unrelated to either dose of the drug or frequency of response.

In general, characteristics of control performance in the operant sessions were typical for the schedules used (see Ferster and Skinner 1957): the response of most birds showed the characteristic FI scallop and postreinforcement pause in the FR, as would be expected in experienced subjects. Average rates of responding for all 15 subjects (mean \pm SE) in the FI were moderate $(0.83 \pm 0.05$ responses $/ \mathrm{s})$, with a quarter life of 2.48 $\pm 0.04 \mathrm{~min}$. Relatively high rates $(2.77 \pm 0.14$ responses/s), were generated in the FR.

Although the effects of apomorphine on elicited behavior were similar for all subjects, their operant behavior revealed individual differences in sensitivity to the drug. These differences were used to form descriptive groups based on the lowest dose that would eliminate operant responding. The doses differed from each other by one full $\log$ unit: Group $1=0.32 \mathrm{mg} / \mathrm{kg}$ $(N=4)$, Group $2=3.2 \mathrm{mg} / \mathrm{kg}(N=9)$, Group 3 $=32.0 \mathrm{mg} / \mathrm{kg}(N=2)$. In general, FI control rates for the three groups were comparable; FR rates were slightly higher in group 2 than in the other groups.

Groups 1 and 2 showed similarities in overall drug effects and differed only in sensitivity of operant behavior to apomorphine. Overall FI and FR response rates for these groups showed no evidence of stimu- 


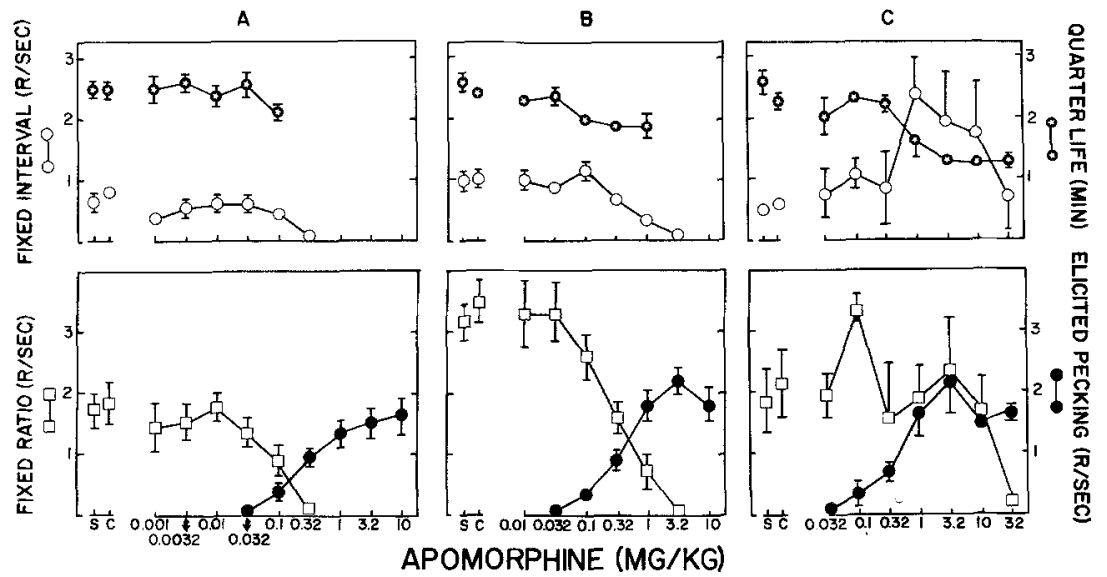

Fig. 1. Effects of apomorphine on average rates of key pecking under the fixed-interval and fixed-ratio components of a mult F15FR30 schedule in pigeons. Fixed-interval quarter life values are plotted against FI rates (upper panel). Rates of elicited pecking are plotted against FR rates (lower panel). Birds are grouped by the dose that eliminated operant responding: A Group $1=0.32 \mathrm{mg} / \mathrm{kg}(N=4), \mathbf{B}$ group $2=3.2 \mathrm{mg} / \mathrm{kg}$ $(N=9), \mathbf{C}$ group $3=32.0 \mathrm{mg} / \mathrm{kg}(N=2)$. Each saline (S), noninjection control $(\mathrm{C})$, and drug data point represents the mean $\pm \mathrm{SE}$ of two observations per bird for each bird in the group. Data are presented for only those doses given to all members of group. Quarter life values are given only when responding occurred. The two control observations were randomly chosen from all the control observations made. Control values were always obtained from the session immediately prior to a drug day

lation (Fig. 1A and B); group means and standard errors either overlapped or fell below control rates throughout the effective dose range. In addition, fixedinterval quarter life values showed dose-related decreases. Note that these dose-dependent decreases in operant responding seen in groups 1 and 2 contrast with the dose-dependent increases found in elicited pecking.

In general, the overall rate-reducing effects of apomorphine resulted from disruptions in FI responding. These pauses occurred both at the start of FI intervals and within the FI components. However, an examination of the patterns of responding throughout the test sessions revealed that local response rates often increased well above control levels when FI pecking occurred without interruption. Such post-pause stimulation in responding occurred reliably in $25 \%$ of the subjects in group 1 and $56 \%$ of the subjects in group 2 . The remainder of the subjects showed either post-pause depression of responding or overall rate-decreases.

Data from group 3 in the operant tests differed both quantitatively and qualitatively from those of groups 1 and 2 (Fig. 1C). Perhaps the most salient result was the close correspondence between the effects of apomorphine on elicited and operant pecking for this group. While the elicited pecking of group 3 showed the same dose-related increases as the other groups, the operant responding of this group, although exhibiting variability, differed from the others in demonstrating the overall rate-increasing rather than the rate-decreasing effects of apomorphine. Fixed-interval responding showed some evidence of stimulation at low doses and pronounced increases at higher doses, and FI quarterlife values showed dose-related decreases. Fixed-ratio responding, particularly at the higher doses, seemed to parallel the effects seen on elicited responding.

To demonstrate the remarkable rate-increasing properties of apomorphine in some birds, Fig. 2 presents several cumulative records of bird 6616 (group 3). This bird was exceptional in both the extent of its FI stimulation and its response over a broad dose range. Saline control FI responding was continuous throughout the session at a moderate rate $(0.50$ responses/s). Fixed-interval stimulation began to appear with $0.032 \mathrm{mg}$ apomorphine $/ \mathrm{kg}$. Although these drug effects lasted only half the session, small pauses appeared in FI responding throughout the rest of the session. Profound stimulation in FI responding was produced by $3.2 \mathrm{mg} / \mathrm{kg}$, yielding a consistent overall FI rate of 3.98 responses/s. Finally, a high apomorphine dose of $32.0 \mathrm{mg} / \mathrm{kg}$ severely disrupted operant behavior, although once resumed FI responding was increased to a rate of 2.2 responses/s. It should be noted that stimulation was not replicated when this dose was repeated in this subject.

\section{Discussion}

The present results corroborate previous findings regarding the ability of apomorphine to elicit pecking in a dose-dependent manner (e.g., Dhawan and Saxena 1960). The degree of differential sensitivity of the operant response to apomorphine is interesting, given the uniformity of the elicited pecking produced by the drug. Such individual differences in sensitivity across birds were surprising as the groups were very uniform. Although the reasons for these differences are unclear, 


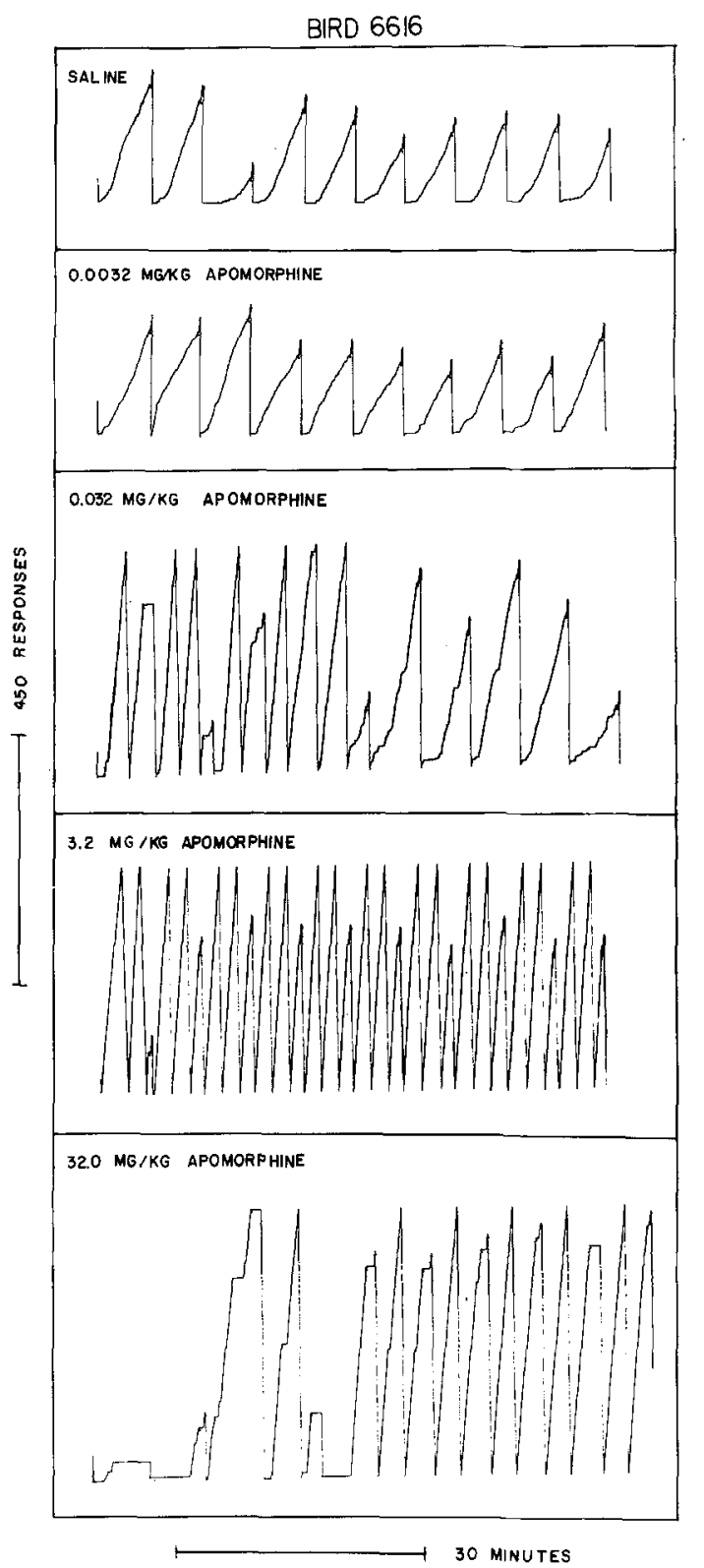

Fig. 2. Cumulative records for bird 6616 (group 3) for saline control and apomorphine $0.0032 \mathrm{mg} / \mathrm{kg}, \quad 0.032 \mathrm{mg} / \mathrm{kg}, \quad 3.2 \mathrm{mg} / \mathrm{kg}$ and $32.0 \mathrm{mg} / \mathrm{kg}$. Key pecking responses were cumulatively recorded by upward movements of the recording pen. Downward deflections indicate a reinforcement. The recorder reset after each complete FIFR sequence

they are probably related to differences in the targets of stereotyped pecking brought about by such factors as the age and behavioral history of the subjects.

What is noteworthy in the present findings is the observed dichotomy in the effects of apomorphine on the rate of operant responding. Groups 1 and 2 demonstrated the dose-dependent, rate-reducing effects of apomorphine on operant behavior which have been reported previously (e.g., De Olivera and Graeff 1972). Group 1 differed from group 2 primarily in its sensitivity to the disturbing effects of stereotypy, although both groups indicated that operant responding decreases as elicited pecking increases. For these subjects, then, increase in stereotyped behavior correlates with a similar decrease in operant responding. Group 3 differed from the others in that these subjects showed stimulated operant responding with the rate-decreasing limb of the dose-response curve shifted to the right. While rate-increasing effects of apomorphine have been reported elsewhere (Weissman 1966; Graeff and De Olivera 1974), the present results are unique in the degree of stimulation observed over a broad dose range.

One interpretation of these results is that the effects of apomorphine on operant behavior depend on the target of induced pecking. Rate-decreasing effects, according to this model, result from the introduction of pauses in operant responding throughout the session during which time stereotyped pecking was directed away from the response key. Rate increases result from stereotyped pecking directed towards the response key. Thus, apomorphine primarily causes interruptions in operant pecking which decrease the overall rate. However, key pecking, when it occurs, is generally stimulated. This interpretation is supported by direct observations of a random selection of subjects while performing in the operant chamber. Subjects from groups 1 and 2 were seen to be pecking the floor and walls of the box at a high rate, while a group 3 subject stood fixedly in front of the operant key and pecked continuously, not even stopping to eat grain when presented. According to this interpretation, then, apomorphine has no important effects on operant responding until elicited pecking is observed.

Although operant and elicited pecking appear superficially similar, the finding of individual differences in sensitivity to apomorphine in operant but not elicited pecking suggests a possible dissociation of the two behaviors. One rationale for the separation of operant and elicited pecking is their response to dopamine receptor blockade. Elicited responding has been found to be more sensitive to the effects of neuroleptics than operant responding. For example, Cheng and Long (1974) found that $1.0 \mathrm{mg}$ haloperidol $/ \mathrm{kg}$ eliminated elicited responding produced by $0.44 \mathrm{mg}$ apomorphine $/ \mathrm{kg}$, while Leander (1975) showed that the same haloperidol dose reduced FR responding by only $40 \%$ and FI responding by $64 \%$. Further, $3.19 \mathrm{mg}$ chlorpromazine $/ \mathrm{kg}$ eliminated pecking induced by $0.44 \mathrm{mg}$ apomorphine/ $\mathrm{kg}$ (Cheng and Long 1974) while $100.0 \mathrm{mg}$ chlorpromazine $/ \mathrm{kg}$ was needed to reduce FR responding $35 \%$ and FI responding $50 \%$ (Leander 1975). The fact that operant pecking continues while elicited pecking is blocked suggests that 
operant behavior is not as directly under the control of dopamine as is elicited behavior.

The separation of apomorphine effects on operant and elicited pecking may have practical ramifications. Van Rossum (1970) has noted that the antagonism of apomorphine- and amphetamine-induced stereotypy is a test of choice for detecting neuroleptic-like activity in animals. Along these lines, the pecking model may be useful in predicting the efficacy of dopamine antagonists as anti-psychotics. For example, an effective neuroleptic such as haloperidol reduces elicited pecking at doses which do not interfere with conditioned pecking. However, bulbocapnine, a dopamine antagonist with poor anti-psychotic properties, reduces elicited pecking only at doses which reduce conditioned pecking as well (J. H. Woods, unpublished data). Thus, the ability of a dopamine blocker to disrupt elicited pecking without affecting operant pecking may be a good predictor of its therapeutic properties.

Acknowledgements. This research was supported in part by NIDA grant DA 00154. Sincere thanks are extended to John Marriott, John Collins, and David Downs for their helpful comments on the manuscript, and to Patrice Yoder for her assistance in collecting the data. These data were presented in part at the 9 th Annual Meeting of the Society for Neuroscience, Atlanta, Georgia, 1979.

\section{References}

Butcher LL (1968) Effects of apomorphine on free-operant avoidance behavior in the rat. Eur $\mathbf{J}$ Pharmacol 3:163-166

Cheng HC, Long JP (1974) Dopaminergic nature of apomorphineinduced pecking in pigeons. Eur J Pharmacol 26:313-320

Costall B, Naylor RJ (1975) Actions of dopaminergic agonists on motor function. In: Caine DB, Chase TN, Barbeau A (eds)
Advances in neurology, Vol. 9. Raven Press, New York, pp $285-297$

De Olivera L, Graeff FG (1972) Comparison between the effects of apomorphine and amphetamine on operant behavior. Eur I Pharmacol 18:159-165

Deshpande VR, Sharma ML, Kherdikar PR, Grewal RS (1961) Some observations on pecking in pigeons. Br $\mathbf{J}$ Pharmacol 17:7-11

Dhawan BN, Saxena PN (1960) Apomorphine-induced pecking in pigeons. Br J Pharmacol 15:285-289

Ernst AM (1967) Mode of action of apomorphine and dexamphetamine on gnawing compulsion in rats. Psychopharmacologia (Berlin) 10:316-323

Ferster CB, Skinner BF (1957) Schedules of Reinforcement. Appelton-Century-Crofts, New York

Frommel ED, Ledubur I von, Seydoux J (1965) Is apomorphine's vomiting action in man and dog equivalent to its chewing effect in guinea pig? Arch Int Pharmacodyn Ther 154:221-230

Graeff FG, De Olivera L (1975) Influence of response topography on the effect of apomorphine and amphetamine on operant behavior of pigeons. Psychopharmacologia (Berlin) 41:127-132

Koster R (1957) Comparative studies of emesis in pigeons and dogs. J Pharmacol Exp Ther 119:406-417

Leander JD (1975) Rate-dependent effects of drugs. II. Effects of some major tranquilizers on multiple fixed-ratio, fixed-interval schedule performance. J Pharmacol Exp Ther 193:689-700

Nymark M (1972) Apomorphine provoked stereotypy in the dog. Psychopharmacologia (Berlin) 26:361-368

Pedersen V (1967) Potentiation of apomorphine effect (compulsive gnawing behavior) in mice. Acta Pharmacol Toxicol (suppl 25) $4: 63$

Saxena PN, Chawla N, Johri MBL, Iqbal S (1977) Nature of receptors involved in apomorphine responses in pigeons. Psychopharmacology 53:89-95

Van Rossum JM (1970) The neuroleptics: Pharmacology. In: Bobon DP, Janssen PAJ, Bobon J (eds) Modern problems of Pharmacopsychiatry, Vol. 5. S. Karger, Basel, pp 23-32

Weissman A (1966) Apomorphine elicitation of key pecking in a pigeon. Arch Int Pharmacodyn 160:330-332

Received June 22, 1979; Final version June 2, 1980 